\title{
SIMULATION OF STRUCTURAL STEEL ERECTION OPERATIONS - A CASE STUDY
}

\author{
Ming-Cong Li ${ }^{1}$, Yu-Ting Lai ${ }^{2}$, Shu-Ping Chang ${ }^{3}$, \\ Yu-Lin Huang ${ }^{4}$, Wei-Chih Wang ${ }^{5}$
}

\author{
${ }^{1.2 .3}$ Graduate Student, ${ }^{4}$ Associate professor, ${ }^{5}$ Assistant professor, Department \\ of Civil Engineering, National Chiao-Tung University, Hsin-Chu, Taiwan
}

\begin{abstract}
In the past decades, several simulation models have been developed to analyze the performance of construction projects and site operations that are fraught with uncertainty. Due the lack of successful practical examples being report, however, the construction industry still has a doubt in using simulation techniques. For this reason, this paper presents a simulation-based example of the site-level structural steel erection operations for a building project located in Taiwan. The example has shown the benefits of using simulation to plan the number of work zones, analyze the resource production rate, and identify critical tasks.
\end{abstract}

Keywords: simulation, structural steel erection, construction operations

1.

In the past decades, several simulation models have been developed to analyze the performance of construction projects and site operations that are fraught with uncertainty. Due the lack of successful practical examples being report, however, the construction industry still has a doubt in using simulation techniques. For this reason, this paper presents a real example of using simulation techniques to support management in dealing with the problems encountered by the site-level structural steel erection operations for a 14-story building project located in Taiwan.

This paper starts with a description of the background of case project. Then the management decisions faced are introduced. Thirdly, the development of the simulation model is presented. Fourthly, the simulated results to support

\section{INTRODUCTION}

management decisions are illustrated. Finally, several comments and suggestions received by the project practitioners on this case study are provided.

2.

\section{CASE PROJECT}

The case project, called the Civil Service Development Institute new construction Project, is located at the center of Taipei, Taiwan. This building project contains three underground floors, and includes a 14-story hotel-like dormitory and three 6story educational, conventional, and office buildings. The project is designed with a mixture of RC (reinforced concrete), SS (structural steel) and SRC (steel and reinforced concrete) structures, and its total budget is about $\$ 42,600,000$ US dollars. 
According to the results shown in a preliminary scheduling study (i.e., critical path method analysis) for this case project, it was identified that the erection operation of structural steel for the 14-story SRC dormitory will be crucial to complete the project on schedule. Therefore, determining appropriate sequences between construction tasks and optimal allocating resources for structural steel erection operations becomes major liabilities and concerns for the project site engineers.

3.

\section{STRUCTURAL STEEL ERECTION OPERATIONS}

As shown in Figure 1, the completion of a typical structural steel story requires six major construction tasks, including: (1) hoisting and assembling of structural steel columns and beams (C/B), (2) deck erecting, (3) temporarily connecting the steel and surveying / aligning, (4) inspecting to check whether the $\mathrm{C} / \mathrm{B}$ and deck are placed as planned, (5) locking out the nuts of high tension bolts (H.T.B.) and welding, and (6) checking horizontal level and final / supplemental painting. In this case project, when the hoisting operations of $\mathrm{C} / \mathrm{B}$ and deck for twelve floors are completed, the tower crane is required to climb up.

The logical relationships between these operational tasks shown in Figure 1 are straightforward. However, at the jobsite, the interactions between these tasks and other involved resources are actually much more complicated. A typical phenomenon of interaction is the competition of limited resources between tasks. Unable to capture this interaction may lead to an optimistic expectation of project duration, and eventually the project cost is also increased.

Figure 1. Tasks for Completing Structural Steel

\section{Erection Operations}

After interviewing with the site engineers who are in charge of the structural steel operation of case project, three decisions required to be made are identified as follows:

(1)

To plan the number of work zones for each construction materials.

(2)

To analyze the production rate of resource for allocating crew workers.

To identify the tasks that dominate the performance of duration.

While current practitioners are experience-based to deal with these decisions, this paper uses simulation techniques to provide solutions.

4.

\section{SIMULATION MODEL}

After defining the decision-making problems, this section describes the details of developed simulation model. As shown in Figure 2, four components for developing a simulation model are needed [3]: types of input information or data required, assumptions, decision variables, and performance measures of the model. The required input data include the involved tasks, task durations, logical relationships between tasks, available 


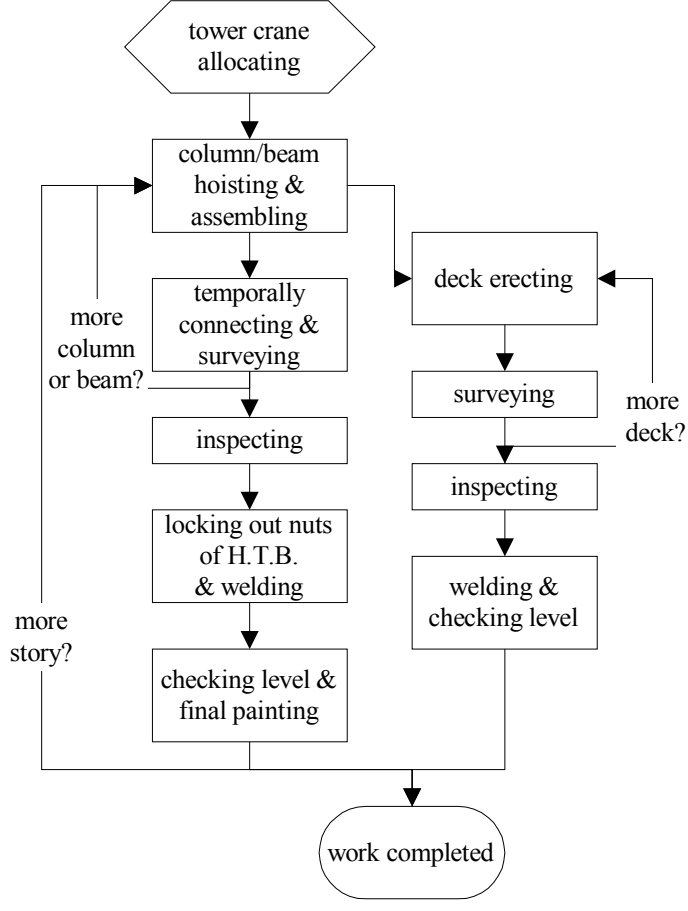

resources, and site conditions (e.g., available work areas and capacity of tower crane). The decision variables are the number of work zones to be divided and the amount of crew workers to be employed. The assumptions simplify certain complexity of the model. And the performance measurements for making decisions generated by the simulation are duration and resource utilization rate.

Figure 2. Components of a Simulation

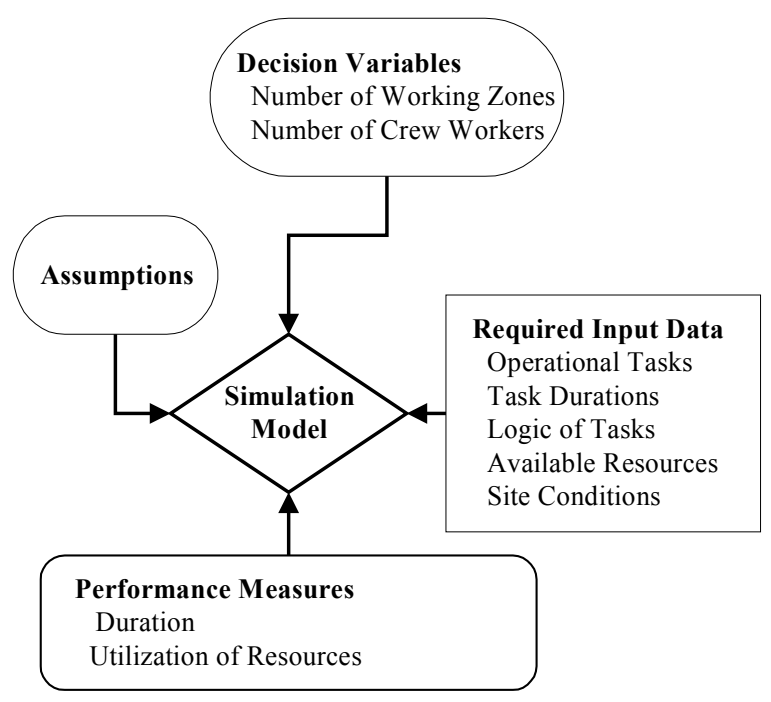

Model

In addition to further illustrate the details of the above four modeling components, the following subsections also explain the simulation language adopted by this case study, the simulation network diagram, and some key features for simulation programming.

\section{Stroboscope Simulation Language}

This paper adopts a simulation language called Stroboscope (State and Resource Based Simulation of Construction Process) for its strong ability to dynamically access the state of simulation and the properties of resource involved in construction operations [3]. A Stroboscope model consists of a series of programming statements that define a network, which is built based on interconnected modeling elements. The modeling elements used in this case study included the Link, Queue, Combi, Normal, Consolidator, and Assembler [3]. Table 1 presents the symbol, name, and general description of Stroboscope elements used in this study. 
Table 1. Modeling Elements of Stroboscope

\begin{tabular}{|c|c|c|}
\hline 1 & Name & General Description \\
\hline & Link & $\begin{array}{l}\text { Connect the nodes (such as queue, combi, normal, consolidator, and assembler); } \\
\text { Indicate the direction of resource flow; } \\
\text { Only specified types of resource flow through it }\end{array}$ \\
\hline & Queue & $\begin{array}{l}\text { Hold idle resources } \\
\text { Associate with a particular resource } \\
\text { Contain characteristic, general and compound types of resource }\end{array}$ \\
\hline & Combi & $\begin{array}{l}\text { Represent the task to be performed with necessary resources } \\
\text { Hold an amount of time equal to its duration } \\
\text { Start when certain conditions are met }\end{array}$ \\
\hline & Normal & $\begin{array}{l}\text { Represent the task to be performed } \\
\text { Hold an amount of time equal to its duration } \\
\text { Start immediately after preceding task ends }\end{array}$ \\
\hline & Consolidato & $\begin{array}{l}\text { Accumulate resources to met certain conditions } \\
\text { Release resources to successors immediately }\end{array}$ \\
\hline & Assembler & $\begin{array}{l}\text { Combine different types of resources as a group } \\
\text { Create a new compound resource }\end{array}$ \\
\hline
\end{tabular}

\section{Required Input Data}

The required data are collected by interviewing with the jobsite superintendents, engineers, foreman, and crew workers. Table 2 summaries the three-point duration data (optimistic time, most likely or possible time, and pessimistic time) for most tasks, except for the tasks of hoisting and assembling for columns and beams.

By disaggregating the hosting and assembling task into six movements (loading, hoisting, angular moving, unloading, assembling and returning), the durations of hoisting and assembling for columns and beams are calculated base on Equations (1) and (2), respectively [1].

$$
\text { Time }_{\text {beam }}=\frac{h}{v_{1}}+\frac{h}{v_{2}}+\frac{20}{v_{3}}+\frac{1}{2 v_{4}}+\frac{R}{v_{5}}-f_{a}\left(\frac{1}{v_{1}}+\frac{1}{v_{2}}\right)+8
$$


$\mathrm{h}$ : height of element assembling (meter)

$f_{a}$ : average height of beam locating (meter)

$\mathrm{R}$ : angular of arm of tower crane moved (degree)

$\mathrm{v}_{1}$ : lifting with low speed (meter/minute)

$\mathrm{V}_{2}$ : landing with low speed (meter/minute)

$\mathrm{v}_{3}$ : speed of loading (meter/minute)

$\mathrm{V}_{4}$ : speed of angular movement (rotation/minute)

$\mathrm{V}_{5}$ : speed of hanger's horizontal movement (meter/minute)

The variable "h" would be varied when assembling column or beam in different story. The factor $\mathrm{R}$ and speeds $\left(\mathrm{v}_{1}, \mathrm{v}_{2}, \mathrm{v}_{3}\right.$, $\mathrm{v}_{4}$, and $\mathrm{v}_{5}$ ) also vary in different stories and different work zones. Note that their durations are thus assumed to be deterministic.

Table 2. Duration Distribution of Tasks (hour/unit)

\begin{tabular}{r|ccc}
\hline & \multicolumn{1}{|l}{ Task } & \multicolumn{2}{l}{$\mathrm{c}$} \\
\hline C/B aligning & 0.15 & 0.20 & 0.25 \\
\hline C/B & 0.20 & 0.25 & 0.33 \\
surveyi & & & \\
ng & & & \\
C/B & 1.13 & 1.50 & 1.88 \\
weldin & & & \\
g & & & \\
\hline Deck erecting & 0.08 & 0.09 & 0.10 \\
\hline Deck aligning & 0.04 & 0.05 & 0.07 \\
\hline Deck surveying & 0.04 & 0.05 & 0.07 \\
\hline Deck welding & 0.15 & 0.20 & 0.25 \\
\hline Inspecting & 2.25 & 3.00 & 3.75 \\
\hline
\end{tabular}

\begin{tabular}{r|ccc}
\hline $\begin{array}{c}\text { Lockin } \\
\mathrm{g} \quad \text { out } \\
\text { nuts }\end{array}$ & 0.30 & 0.40 & 0.50 \\
\hline Checking level & 2.25 & 3.00 & 3.75 \\
\hline Final painting & 3.00 & 4.00 & 5.00 \\
\hline
\end{tabular}

$\mathrm{C} / \mathrm{B}$ : columns and beams

\section{Decision Variables}

The decision variables in this case study are the amount of work zones to be divided and amount of crew workers to be employed. A work zone is the place for stacking the $\mathrm{C} / \mathrm{B}$ structural steel materials. As implied in Equations (1) and (2), the durations of $\mathrm{C} / \mathrm{B}$ hoisting and assembling tasks actually depend on the location of work zones. It is assumed that materials hoisted and assembled by the tower crane from the same zone will have the same speed and same rotation angular of arm of tower crane. In other words, the durations of hoisting and assembling tasks at the same zone will have same durations. Determining the amount of work zones to be divided affect the duration of hoisting and assembling task and also the total duration of the operation. The amount of crew workers to be employed has to with the cost required to finish the job. This supports the management of the strategies of resource allocation.

By changing the values of decision variables, the simulation model generates different results. The optimal amounts of work zones and crew workers are the ones that can produce the shortest duration of the operation. 


\section{Assumptions}

The main assumptions made in this simulation model include:

(1) Only single tower crane is used and its location at jobsite is fixed. This is because the number and jobsite location of tower crane have been determined when the simulation analysis is conducted.

(2) Bad weather and other unexpected uncertainties are ignored. Possible unexpected uncertainties such as the temporary stoppage required by safety governmental officers, and late delivery of materials for structural steel columns and beams.

(3) The "hoisting and assembling" task is somewhat simplified. The task actually consists of a series of sub-tasks, including moving structural steel to the lifting location, clipping the steel, hoisting, and assembling. However, for simplicity, it is assumed that the durations of moving structural steel to the lifting location and clipping the steel to the tower crane are zero.

\section{Simulation Network Diagram}

As shown in Figure 3, the interactions of resources between tasks are graphically captured in the simulation model. Note that this graphical network was verified by the project superintendent. And the figure only represents a cycle (one floor) of the structural steel erection operation. More detailed input data and other characteristics of the case project data, such as the number of work zones and number of floors, are captured by Stroboscope programming statements.

In the same figure, it can also be seen that crew workers are shared by the tasks of $\mathrm{C} / \mathrm{B}$ hosting \& assembling, locking out nuts of H.T.B., C/B welding, deck erecting and welding. According to the common practice in the field, the priority of resource competition is first given to column and beam hoisting \& assembling, and then deck erecting.

\section{A Key Feature of Programming}




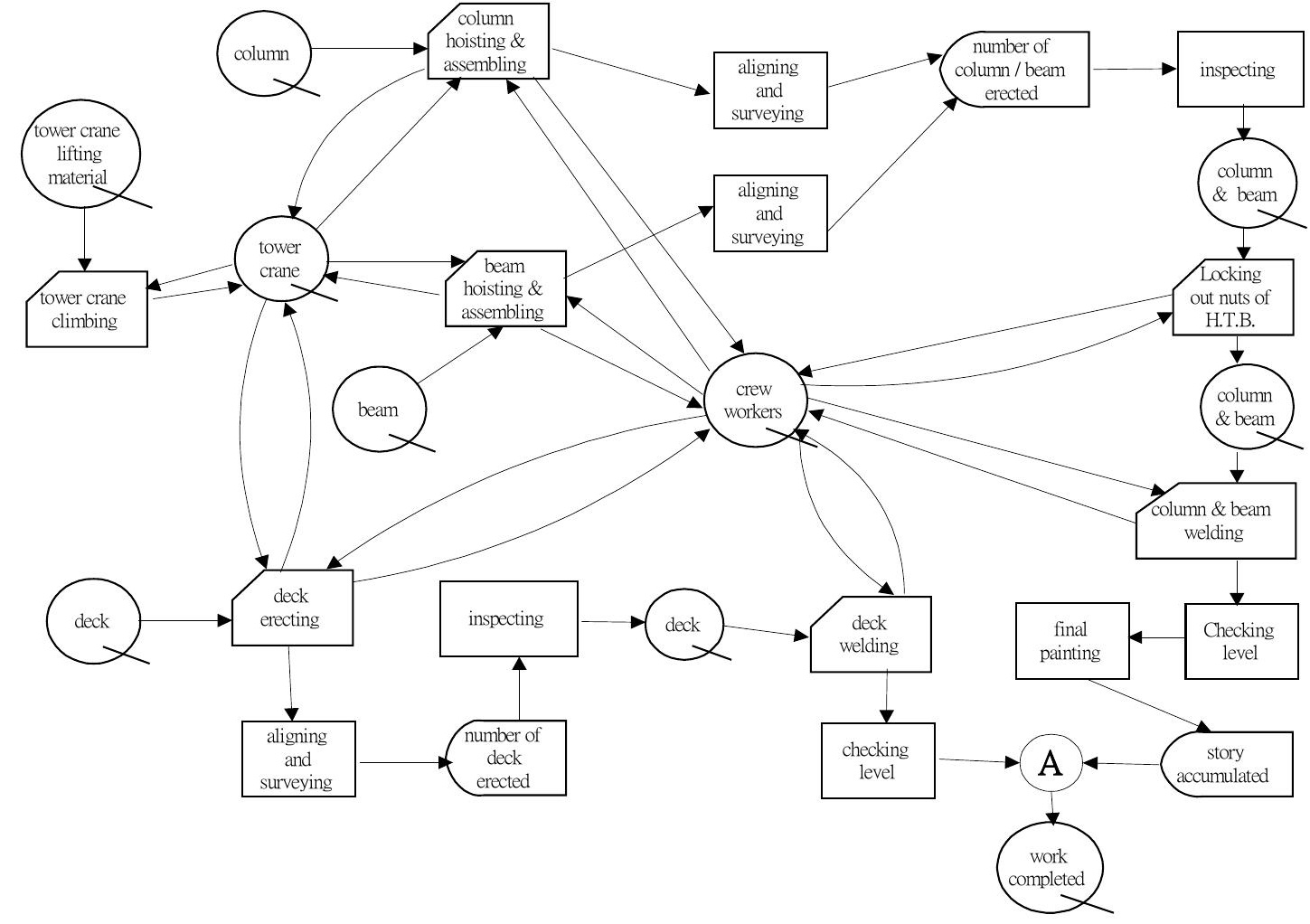

All the network elements show in Figure 3 is captured by Stroboscope programming statements. One of the key features of programming the simulation model is to reflect the progression of 14 cycles (floors or stories) for the 14-story building. That is, if the first cycle is finished, how the simulation automatically continues to execute the tasks for the second cycle? This question can be best answered by the flowchart presented in Figure 4.

Also to ensure that the amount of columns and beams are completed for each work zone is done by the Stroboscope's Consolidator statement. And the programming concept of Do-Loop is used to repeatedly execute the tasks of each of the 14 cycles.

Figure 3. Network Diagram of Simulation Model for One Cycle 


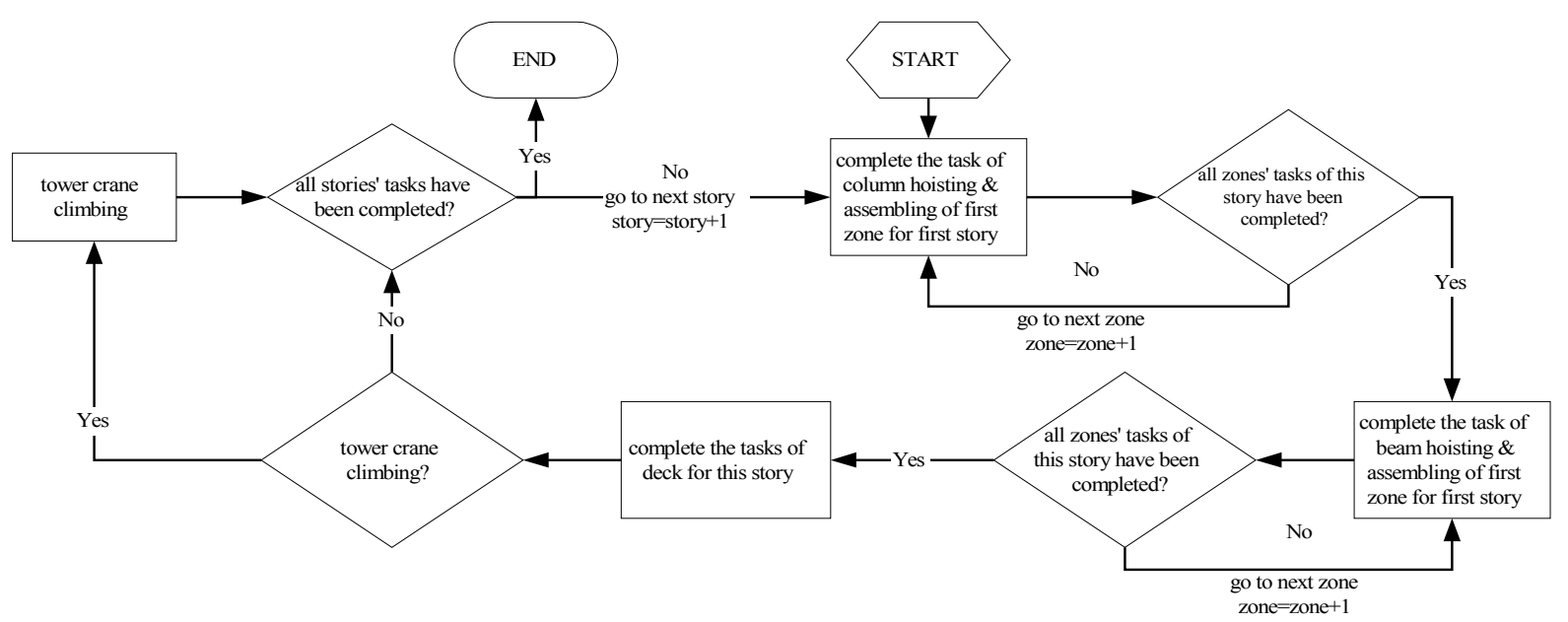

Figure 4. Flow Chart of Modeling the Progression of Cycles

\section{RESULTS AND DISCUSSIONS}

The simulation results can be presented in three parts: impact of varying number of work zones, utilization of resources, and dominant tasks for each

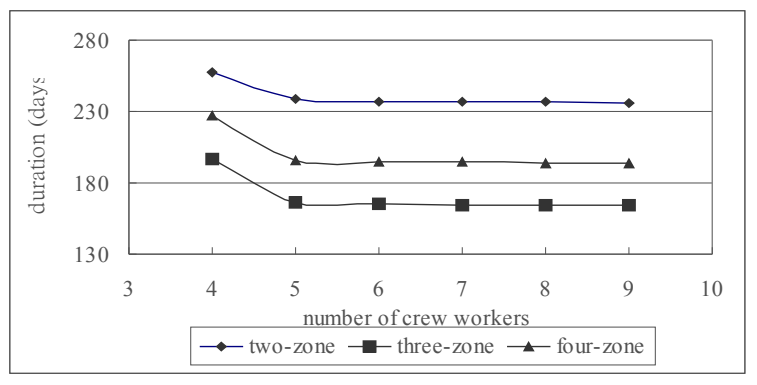

story.

\section{Impact of Varying Number of Work Zones}

Figure 5 shows the durations of executing the 14-story structural steel operation under different divisions of work zones and number of crew worker. From the figure, it can be found that:

(1)

Possible durations can be ranged from 164 to 257 days.

(2)

Dividing into three zones can produce the shortest duration, i.e., about 164 working days. That is, C/B structural steel should be stacked at three designated zones or areas.

(3)

Dividing into more zones does not necessarily lead to a shorter duration. For example, the duration of 4-zone scenario produces longer duration than 3-zone scenario.

(4)

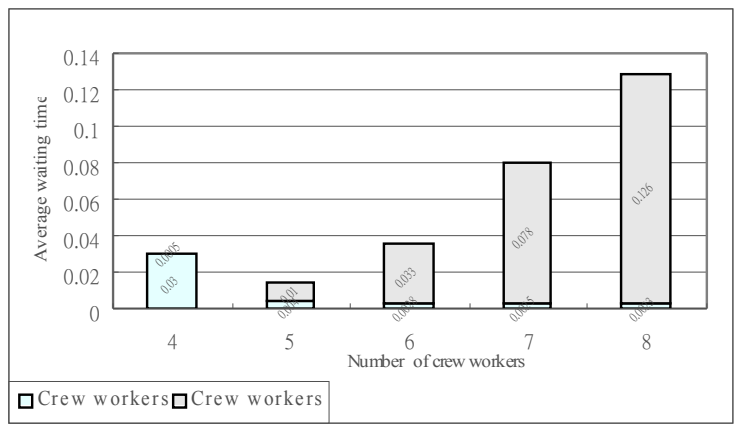

Using six crew workers under three zones can result into the shortest duration. And adding more than six crew workers has no impact on the duration.

Figure 5. Duration Impact due to Varying Number of Zones and Crew Workers

\section{Utilization of Resources}

Here, the resources of interest are the tower 
crane and crew workers. Figure 6 shows the average waiting times for both tower crane and a crew worker for one cycle under the 3-zone scenario. It can be observed that the more crew workers, the longer waiting time for a crew worker, and the shorter waiting time for tower crane (i.e., busying in hoisting and assembling).

Figure 6. Average Waiting Time of Tower Crane and Crew Worker in One Cycle

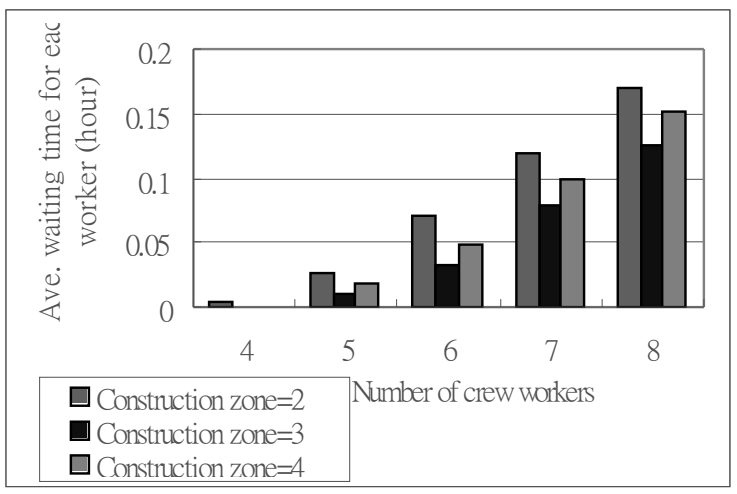

Figure 7. Comparison of Average Waiting Time of

Crew Workers in Varying Zoning

However, as shown in Figure 5, increasing the number of crew workers (adding more labor cost) does not shorten the duration. It may due to the limitation of productivity of tower crane. This phenomenon is the same for the zone- 2 and zone- 4 scenarios as can be seen in Figure 7.

\section{Dominant Tasks for each Floor}

In this case study, to identify dominant tasks for supporting management is to determine which activities control the total duration of the steel erection operation. It is similar to identify to the so-called critical path. As shown in Table 3, the durations of three paths for each of the 14 floors are presented. The tasks located at these three paths are:

(1)

Column path: hoisting and assembling of column $\rightarrow$ aligning \& surveying for column $\rightarrow \mathrm{C} / \mathrm{B}$ inspecting $\rightarrow$ locking out nets of H.T.B. $\rightarrow$ C/B welding $\rightarrow \mathrm{C} / \mathrm{B}$ checking level.

(2)

Beam path: hoisting and assembling of beam $\rightarrow$ aligning \& surveying for beam $\rightarrow \mathrm{C} / \mathrm{B}$ inspecting $\rightarrow$ locking out nets of H.T.B. $\rightarrow$ C/B welding $\rightarrow \mathrm{C} / \mathrm{B}$ checking level.

(3) Deck path: deck erecting $\rightarrow$ aligning \& surveying for deck $\rightarrow \mathrm{C} / \mathrm{B}$ inspecting $\rightarrow$ deck welding $\rightarrow$ deck checking level.

As can be found in the same table, the column path has a longest duration for $1^{\text {st }}, 4^{\text {th }}, 7^{\text {th }}, 10^{\text {th }}$, and $13^{\text {th }}$ floor, respectively. And the beam path dominates for the rest of floors. These results may be expected because of two reasons: (1) the tasks of hoisting and assembling for columns have a higher priority to compete the tower crane and crew workers than the tasks of hoisting beams and erecting decks. And (2) since the height of a structural steel is three floor tall, there are actually only the five floors needed to execute the task of hoisting and assembling for columns.

Table 3. Path Durations for Each Story (hours)

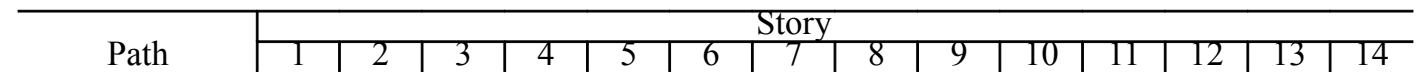




\begin{tabular}{l|r|r|r|r|c|r|r|r|r|r|r|r|r|r}
\hline Column Path & $\mathbf{2 4 5}$ & - & - & $\mathbf{2 9 0}$ & - & - & 292 & - & - & 290 & - & - & 195 & - \\
Beam Path & 234 & $\mathbf{2 3 3}$ & $\mathbf{2 1 8}$ & 280 & $\mathbf{2 8 0}$ & $\mathbf{2 1 4}$ & 281 & $\mathbf{2 7 9}$ & $\mathbf{2 7 8}$ & 280 & $\mathbf{2 7 8}$ & $\mathbf{2 8 3}$ & 184 & $\mathbf{1 7 5}$ \\
\hline Deck Path & 164 & 165 & 164 & 165 & 164 & 185 & 165 & 165 & 185 & 165 & 166 & 185 & 165 & 138 \\
\hline
\end{tabular}

\section{CONCLUSIONS}

This paper has demonstrated the benefits of applying simulation techniques to support management in dealing with three site-level problems for a practical project: planning the number of work zones to stack materials, determining the amount of crew workers, and identifying the crucial tasks to be paid more attention to.

After presenting the simulation results to the project superintendent, several comments and suggestions to this case study are concluded. Firstly, since the use of network diagrams allows to "visualize" the modeling process (such as Figure 3), simulation results tend to be more reasonable than the ones provided by other mathematical models. Secondly, the decision variables (such as changing the number of zones and crew workers) used by the simulation model for this case study are "acceptable" to the decision-makers. For example, analyzing the number of tower cranes required to be employed will be useless for the case project, since the decision has already been decided. Finally, it is agreed that the reason why the predicted duration is shorter than the actual duration in the field for about 16 days (i.e., 164 days versus 180 days) may be due to several stoppages of safety violations occurred during the operation period.

\section{REFERENCES}

[1] Chen, M.Y. and Chang, W.T., "Tower crane site layout and cost estimation for steel structure erection - A GIS Approach," Journal of the Chinese Institute of Civil and Hydraulic Engineering, Vol. 11, No. 3, pp. 567-578, 1999.

[2] Martinez, J.C., State and Resource Based Simulation of Construction Process, Ph.D. Dissertation, The University of Michigan, Ann Arbor, 1996.

[3] Slaughter, E. Sarah, "Assessment of construction processes and innovations through simulation," Journal of Construction Management and Economics, Vol. 17, pp. 341-350, 1999. 